\title{
Endoscopic removal of migrated esophageal stent: the "cap-assisted" method
}
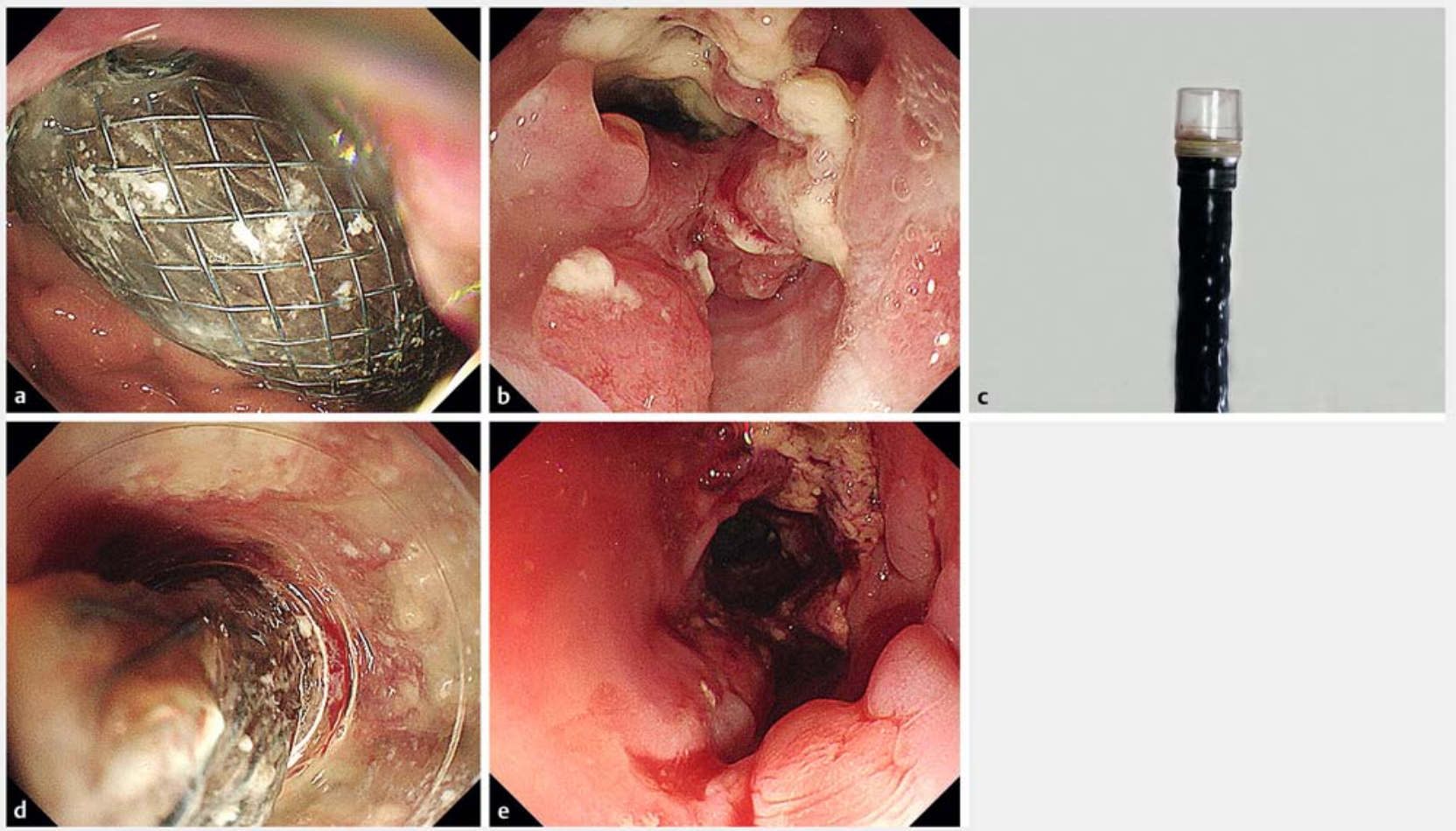

- Fig. 1 The process of removing the migrated esophageal stent. a The migrated stent was located in the gastric body. b Mild stenosis existed in the middle and lower esophagus caused by a tumor. $\mathbf{c}$ The transparent cap was fixed on the tip of the endoscope. $\mathbf{d}$ The proximal end of the stent was pulled back into the transparent cap. e Repeat endoscopy after removing the stent.

A 65-year-old man presented with symptoms of dysphagia, abdominal pain, and retrosternal pain, and was eventually diagnosed with metastatic adenocarcinoma of the cardia. The patient was treated with palliative chemotherapy and esophageal stenting to relieve symptoms. Abdominal pain and dysphagia reappeared after only 3 months and he returned to the local hospital. Painless endoscopy disclosed that the stent had migrated and was located along the great curvature of the gastric body ( $\boldsymbol{F i g . 1} \mathbf{a}$ ). Repeated attempts to remove the stent failed. The patient then came to our hospital for treatment. Endoscopy revealed mild stenosis in the middle and lower esophagus caused by a tumor ( $\triangleright$ Fig. $\mathbf{1} \mathbf{b}$ ), and the standard gastroscope $(9.8 \mathrm{~mm}$ ) encountered slight resistance through the narrow
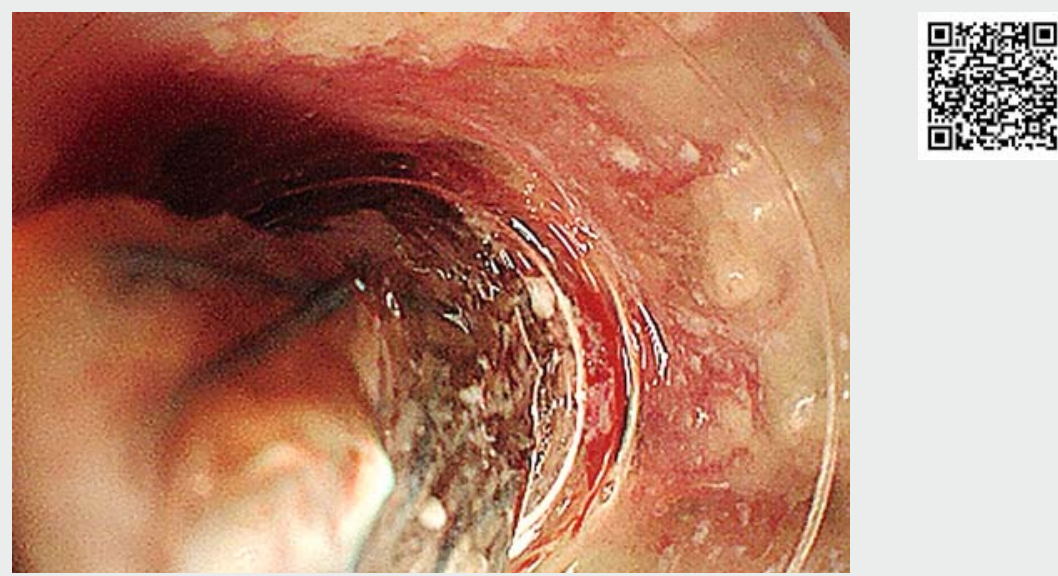

$\square$ Video 1 Endoscopic removal of the migrated esophageal stent using the "cap-assisted" method. 
section. Under direct view of the endoscope, we grasped the fixing wire of the stent with a rat-tooth forceps and pulled it back it until the proximal end of the stent was fully retracted into the transparent cap (Olympus MH-463) to reduce the size of the stent and prevent its proximal end from damaging the esophageal mucosa during the removal process ( Fig. $1 \mathbf{c}, \mathbf{d}$ ). Afterwards, the stent was gently removed through the esophageal stricture, the upper esophageal sphincter, and the throat ( $\triangleright$ Video 1 ). The whole procedure was completed in fewer than 6 minutes. Repeat endoscopy revealed mild bleeding from the surface of the tumor but no lesions elsewhere ( $\triangleright$ Fig. 1 e). Esophageal stent migration is a common complication with an incidence of $14.6 \%$ [1]. Distal migration of the stent can lead to complications such as intestinal obstruction and impaction [2,3]. Furthermore, it is more difficult to remove the stent from patients with a tumor-involved circumferential esophageal mucosa. Many different approaches have been described, such as the "grasper and pusher" method [4]. We provide a new safe and effective method to remove the migrated stent.

Endoscopy_UCTN_Code_CPL_1AH_2AD.

\section{Competing interests}

The authors declare that they have no conflict of interest.

The authors

\section{Xubiao Nie, Chaoqiang Fan, Shiming Yang,} Jianying Bai

Department of Gastroenterology, Second Affiliated Hospital, Army Medical University, Chongqing, China

\section{Corresponding author}

\section{Jianying Bai, MD}

Department of Gastroenterology, Second Affiliated Hospital, Army Medical University, No.183 Xinqiao Main Street, Shapingba District, Chongqing 400037, China

Fax: +86-023 86763169

drbaijy9909@163.com

\section{References}

[1] Wang C, Lou C. Randomized controlled trial to investigate the effect of metal clips on early migration during stent implantation for malignant esophageal stricture. Can J Surg 2015; 58: 378-382

[2] Begbie S, Briggs G, Levi ]. A late complication of palliative stenting of malignant oesophageal obstruction. Aust N Z J Med 1996; 26: 115
[3] Ho HS, Ong HS. A rare life-threatening complication of migrated nitinol self-expanding metallic stent (Ultraflex). Surg Endosc 2004; 18: 347

[4] Martins B, Sorbello MP, Retes F et al. Endoscopic removal of migrated esophageal stent-the "grasper and pusher" method. Endoscopy 2012; 44 (Suppl. 02): E10

Bibliography

Endoscopy 2021; 53: E267-E268

DOI 10.1055/a-1260-2940

ISSN 0013-726X

published online 1.10 .2020

(c) 2020. Thieme. All rights reserved. Georg Thieme Verlag KG, Rüdigerstraße 14, 70469 Stuttgart, Germany

\section{ENDOSCOPY E-VIDEOS}

https://eref.thieme.de/e-videos

口回 Endoscopy E-Videos is a free access online section, reporting 自社: on interesting cases and new

techniques in gastroenterological endoscopy. All papers include a high quality video and all contributions are freely accessible online.

This section has its own submission website at https://mc.manuscriptcentral.com/e-videos 